\title{
Do pensamento abissal à ecologia de saberes na escola: reflexões sobre uma experiência de colaboração'
}

Marco Túlio de Urzêda-Freitas"

\section{Resumo}

Neste trabalho, compartilho algumas reflexões a respeito da minha experiência de colaboração com uma professora de inglês da rede estadual de ensino em Goiânia (G0). A pesquisa teve por objetivo investigar os aspectos e desafios que permeiam a colaboração entre pesquisadores e professores. Para fundamentar as reflexões, busco respaldo em teorias que exploram: os aspectos e desafios da educação regular pública no Brasil; as condições de ensino e aprendizagem de línguas estrangeiras, em especial, inglês, em escolas públicas; as políticas da formação de professores de línguas estrangeiras; a relação entre pesquisa/reflexão colaborativa e formação de professores; e, por fım, a disparidade que separa a universidade e a escola na produção de conhecimentos pedagógicos. 0 estudo se caracteriza como uma pesquisa colaborativa e emancipatória, uma vez que encoraja a produção colaborativa de saberes entre um pesquisador e uma professora. Por meio de um questionário, três sessões reflexivas e um diário de campo, foram selecionados dois aspectos principais para serem analisados: os entraves iniciais da colaboração entre os participantes e as reflexões que os participantes produziram na e por meio da ação colaborativa. A análise desses aspectos mostrou que a pesquisa colaborativa pode reduzir as linhas abissais que separam pesquisadores, enquanto articuladores da teoria, e professores em sua prática, abrindo espaço para uma ecologia de saberes na escola.

\section{Palavras-chave}

Escolas regulares públicas - Ensino de línguas estrangeiras/inglês - Colaboração - Ecologia de saberes.
I- Agradeço às professoras Camila Leopoldina Batista dos Santos, Marcela Ferreira Marques, Nilvânia Damas Silva Lima e Viviane Pires Viana Silvestre a leitura deste texto, e à professora Vera, a abertura, confiança e, sobretudo, as experiências e reflexões compartilhadas.

II- Universidade Federal de Goiás, Goiânia, GO, Brasil.

Contato: marcotulioufcultura@gmail.com 


\title{
From abyssal thinking to the ecology of knowledge in school: reflections on an experience of collaboration'
}

Marco Túlio de Urzêda-Freitas"

\begin{abstract}
In this work, I share some reflections about my experience of collaboration with an English teacher in the state education system in Goiânia city, Goiás state, Brazil. The research aimed to investigate the issues and challenges that permeate the collaboration between researchers and teachers. To substantiate the discussion, I seek support in theories that explore: aspects and challenges of regular public education in Brazil; the conditions of teaching and learning foreign languages, especially English, in public schools; policies of foreign language teacher education; the relationship between collaborative research / reflection and teacher education; and, finally, the disparity between universities and schools in the production of pedagogical knowledge. This is a collaborative and emancipatory study as it encourages the collaborative production of knowledge between a researcher and a teacher. Through a questionnaire, three reflection sessions and a field diary, two main aspects were selected for analysis: the initial barriers to collaboration between the participants; and the reflections that participants produced in and through collaborative action. The analysis of these aspects showed that collaborative research can reduce the abyssal lines that separate researchers, as articulators of the theory, and teachers in their practice, making room for an ecology of knowledge in school.
\end{abstract}

\section{Keywords}

Regular public schools - Foreign languages/English teaching Collaboration - Ecology of knowledge.

I- I would like to thank Professors Camila Leopoldina Batista dos Santos, Marcela Ferreira Marques, Nilvânia Damas Silva Lima and Viviane Pires Viana Silvestre for reading this text, and teacher Vera, for the openness, trust, and above all, the experiences and reflections shared.

II- Universidade Federal de Goiás, Goiânia, GO, Brasil.

Contact:marcotulioufcultura@gmail.com 
Envisioning a future of global peace and justice, we must all realize that collaboration is the practice that

will most effectively enable everyone to dialogue together, to create a new language of community and mutual partnership. (bell hooks)

Neste texto, compartilho algumas reflexões que são fruto da minha experiência de colaboração com uma professora de língua estrangeira - inglês - da rede estadual de ensino em Goiânia (G0). Para refletir a respeito dessa experiência, busco respaldo em dois conceitos: pensamento abissal e ecologia de saberes. Conforme Santos (2010), o pensamento abissal consiste em um sistema de distinções visíveis e invisíveis. As distições invisíveis

[...] são estabelecidas através de linhas radicais que dividem a realidade social em dois universos distintos: o universo deste lado da linha e o universo do outro lado da linha. A divisão é tal que o outro lado da linha desaparece enquanto realidade, torna-se inexistente, e é mesmo produzido como inexistente. Inexistência significa não existir sob qualquer forma de ser relevante ou compreensível. (SANTOS, 2010, p. 32, grifos do autor)

Segundo o autor, uma das principais características do pensamento abissal é a impossibilidade da copresença entre os dois lados da linha que divide a realidade social. No que se refere ao conhecimento, o pensamento abissal consiste na autoridade que a ciência moderna tem para determinar o que é verdadeiro e o que é falso, o que é válido e o que é descartável, o que é visível e o que é invisível. Consequentemente, vários saberes são colocados à margem da realidade social e, por conseguinte, levados à condição de epistemologias marginais.

Todavia, Santos (2010) acredita que esse apartheid epistemológico pode ser desconstruído através do que ele denomina ecologia de saberes. Trata-se de uma epistemologia pós-abissal que requer a valorização da pluralidade interna da ciência, bem como "a interação e a interdependência entre os saberes científicos e outros saberes, não-científicos" (SANTOS, 2010, p. 57).

Tal discussão nos leva a refletir a respeito das divisões invisíveis que permeiam a relação entre a universidade e a escola. Afinal, como as linhas do pensamento abissal manifestam-se nessa relação? Que saberes estão desse lado da linha e quais estão do outro lado da linha da realidade social? Como desestabilizar as linhas invisíveis que separam teoria e prática? Como estabelecer uma ecologia de saberes entre pesquisadores ${ }^{1}$ e professores?

No decorrer do texto, procuro focalizar esses e outros questionamentos tendo como referência os aspectos e desafios da colaboração entre pesquisadores e professores, os quais, ao entrecruzarem suas vozes, podem abrir espaço para uma ecologia de saberes na escola, diminuindo o abismo que separa os conhecimentos visíveis - os acadêmicos - dos conhecimentos invisíveis - os não acadêmicos.

0 estudo foi desenvolvido em uma escola da rede estadual em Goiânia (G0), contando com a participação de um pesquisador (o autor deste artigo) e de uma professora de inglês (Vera, codinome utilizado para preservar a sua identidade). Embora um dos objetivos tenha sido promover mudanças no cotidiano da escola e na prática da referida professora, enfatizarei, neste texto, as reflexões colaborativas que os participantes fizeram a respeito dos temas levantados pela professora no decorrer da investigação. Desse modo, as perguntas que orientam a discussão do presente artigo são: como os saberes e as experiências do pesquisador e da professora se entrecruzam no processo de reflexão colaborativa sobre questões e problemas pedagógicos diversos? Como ambos conseguem, a partir de seus

1- Este texto foi originalmente escrito evidenciando-se as formas masculina e feminina em todas as palavras que requerem a marcação de gênero. Isso porque, a meu ver, o dito genérico masculino funciona como uma estratégia de apagamento linguístico das mulheres. 
respectivos saberes e experiências, abrir espaço para uma ecologia de saberes na escola?

A seguir, apresento os pressupostos teóricos do estudo. Na primeira seção, exploro algumas questões relacionadas ao ensino de línguas estrangeiras (doravante LE) em escolas regulares públicas e à formação de professores de LE no Brasil. Na segunda, enfatizo a relação entre a universidade e a escola na produção de conhecimentos pedagógicos, tendo como base os princípios da pesquisa colaborativa.

\section{Educação pública, ensino de línguas estrangeiras e trabalho docente}

Algebaile (2009) acredita que os problemas da educação pública no Brasil decorrem de uma ampliação para menos: os pobres chegam à escola e a escola deixa de cumprir o seu papel, passando de um lugar de aprendizagem a um lugar de problemas. No entanto, a autora alega que a escola que chega aos pobres não pode ser entendida como um mero malogro de projetos, mas como resultado do processo de formação do Estado brasileiro. Em outras palavras, o insucesso de projetos, a carência de investimentos, o descompasso entre quantidade e qualidade, entre outros problemas, devem ser vistos como:

[...] expressões do lugar secundário que as funções educativas ocupam na formação da escola pública brasileira, tendo em vista o papel que ela passa gradualmente a assumir na gestão da pobreza. (ALGEBAILE, 2009, p. 28, grifo da autora)

Na mesma linha de raciocínio, Zagury (2009) afirma que os problemas da educação devem ser analisados com base no sistema e não na suposta incompetência ou má vontade dos professores. De acordo com a autora, se queremos evitar novos fracassos, devemos ouvir aqueles que ensinam nas salas de aula antes de sugerirmos outros projetos. Entretanto, a autora adverte:
[...] quando falo em ouvir, é ouvir, em escala representativa, buscando primeiro esclarecer a proposta, em seguida, discutir, analisar, saber o que pensam e como encaram, em termos concretos, aqueles que irão executar. (ZAGURY, 2009, p. 19, grifos da autora)

0 que está implícito nessa fala é a ideia de que os pesquisadores conhecem mais as teorias, os métodos e as técnicas de ensino, enquanto os professores conhecem mais a prática, visto que lidam diariamente com as complexidades do processo educativo.

Já Celani (2001) parte da seguinte pergunta para refletir a respeito da relevância social dos professores de LE no Brasil: afinal, o que é o ensino de LE, uma ocupação ou uma profissão? Embora acredite que o fato de os professores de LE atuarem em uma área com características próprias remete ao exercício de uma profissão, a autora lembra que, para serem reconhecidos como profissionais da educação, esses professores devem manter um compromisso de qualidade com seus alunos, com a sociedade e consigo mesmos. No que se refere ao processo formativo, Celani (2001) argumenta que a carreira dos professores de LE começa a partir do momento em que saem da universidade, pois é quando terão a oportunidade de se engajar em uma prática reflexiva, podendo "alcançar o domínio da complexidade e da imprevisibilidade, que é o que [encontrarão] no mundo, na escola, na sala de aula" (CELANI, 2001, p. 39).

Também Leffa (2001, p. 361) acredita que a formação docente "é um trabalho de muitos anos, que apenas inicia quando o aluno sai da universidade”. Essa ideia nos leva a considerar as várias críticas que têm sido feitas à formação de professores de LE nas universidades brasileiras. Muitos profissionais da área alegam, por exemplo, que o que se aprende no contexto acadêmico não se aplica ao contexto escolar. Já outros afirmam que as teorias acadêmicas podem e/ou devem ser ressignificadas à luz 
da experiência cotidiana. 0 fato, no entanto, é que os professores da educação regular não devem "apenas querer ouvir o que os especialistas têm a dizer, e muito menos esperar fórmulas prontas", mas também "trazer suas ideias e trocar experiências com os colegas de sua profissão" (LEFFA, 2001, p. 363). 0 autor conclui que a formação de professores de LE competentes, críticos e comprometidos com a educação é uma tarefa complexa e muito difícil de ser realizada por completo em um curso de graduação, por envolver aspectos linguísticos e políticos da natureza humana.

A formação de professores de LE politicamente situados requer uma compreensão de que a língua, seja ela qual for, está imersa em lutas sociais, econômicas e políticas. No caso do inglês, mais especificamente, Cox e Assis-Peterson (2001) afırmam que não podemos deixar de avaliar criticamente as implicações do nosso trabalho na produção e reprodução das desigualdades sociais. Essa postura reflete as promessas de uma pedagogia crítica no ensino de LE, em especial, de inglês, o que parece distante da realidade de muitos professores no Brasil.

As autoras realizaram uma pesquisa com 20 professores de inglês que atuam na cidade de Cuiabá (MT), tendo por objetivo investigar o grau de familiaridade que esses profissionais tinham com a pedagogia crítica. Em linhas gerais, o estudo mostra que a pedagogia crítica parece estar sendo foco de especulações apenas no mundo acadêmico, reforçando o abismo que separa pesquisadores e professores. Dito de outra forma, a pedagogia crítica no ensino de inglês parece ser

[...] vítima da grande divisão que, no mundo capitalista, separa a pesquisa do ensino, a teoria da prática, aqueles que pensam daqueles que ensinam, aqueles que propõem daqueles que aplicam. Esse descompasso é o calcanhar de Aquiles da educação, instância em que os dois pólos deveriam interagir ininterruptamente. (COX; ASSIS-PETERSON, 2001, p. 32)
A partir dessa constatação, as autoras recomendam a pesquisa colaborativa como instrumento de diálogo entre pesquisadores e professores. Afınal, conforme salientam, chegamos a um ponto em que ou "investimos na construção de uma narrativa polifônica com os professores de inglês, ou nos calamos" (p. 33, grifo das autoras).

Emoutra oportunidade, CoxeAssis-Peterson (2008) fazem uma discussão sobre os fatores que emperram o ensino de inglês nas escolas regulares públicas do Brasil. Entre esses fatores, destacam: a total desvalorização da profissão; a falta de tempo para estudar; a carência de programas de formação continuada; o baixo status das LE na grade curricular; a incompatibilidade entre teoria e prática; e a distância entre universidade e escola. Apoiando-se na ideia de que o mundo global fala inglês, as autoras ressaltam a importância da disciplina de inglês na formação básica dos alunos no mundo contemporâneo. Além disso, defendem a elevação dos professores à posição de protagonistas dos projetos e propostas de mudança, já que são eles que terão de colocá-los em prática nas escolas.

\section{Pesquisa colaborativa e formação de professores}

Segundo Telles (2002), há várias razões que levam à perpetuação do abismo que separa universidade e escola, entre as quais: pouca quantidade de alunos iniciados à pesquisa na graduação; falta de uma disciplina que oriente os alunos na prática da pesquisa; e falta de ênfase na dimensão ética da pesquisa em educação. Consequentemente, a grande maioria dos pesquisadores formados em cursos de licenciatura chega às salas de aula com os seus equipamentos para unicamente estudar a prática dos professores. 0 autor acredita que investigações dessa natureza têm pouco a contribuir com a formação continuada dos docentes e com o desenvolvimento da escola, pois continuam a reproduzir a ideia de que a universidade detém as respostas para todos os problemas da educação. 
Para Telles (2002), a pesquisa educacional deve ser emancipatória, o que significa evitar a relação de dependência que normalmente se estabelece entre pesquisadores e professores. Esse tipo de pesquisa requer a produção de contextos nos quais "o professor possa adquirir instrumentos e desenvolver a prática da reflexão e o desenvolvimento de ações voltadas para a melhoria de seu trabalho pedagógico em sala de aula" (TELLES, 2002, p. 97). Em outras palavras, as pesquisas de natureza emancipatória

[...] promovem uma relação de parceria com o pesquisador - uma posição do professor enquanto "agente" da investigação, em oposição à posição de "sujeito". Também tratam o professor como um ser sabente de sua prática pedagógica e dotado de um potencial e capacidade para a reflexão... (TELLES, 2002, p. 98)

Nesse tipo de pesquisa, pesquisadores e professores trabalham em parceria, tentando produzir sentidos sobre e para o fazer pedagógico. 0 desenvolvimento de pesquisas emancipatórias corrobora a ideia de que pesquisa e ensino não podem ser concebidos como dois mundos distintos. Embasada pelas reflexões de Stetsenko e Arievitch (2002), Mateus (2009) afirma que o exercício da ciência e o exercício pedagógico representam diferentes lados da mesma realidade. A autora sugere um modelo materialista-dialético de pesquisa, o qual visa à transformação das realidades socioeducacionais. Tal modelo vai de encontro às tensões entre teoria e prática, as quais, no decorrer das décadas de 1980 e 1990, aumentaram a distância entre pesquisadores e professores. Uma das razões apontadas por Mateus (2009) para justificar esse distanciamento está no fato de que vários trabalhos, inclusive aqueles de viés colaborativo, acabam sendo realizados sobre ou para o outro, e não com o outro. Essa percepção, que dialoga com as discussões de Cameron et al., (1992), leva-nos a considerar que
[...] as representações culturais-sociais que a academia produz dos professores que investiga contribuem para fortalecer o status do pesquisador sobre o professor e para reproduzir as desigualdades entre ambos. (MATEUS, 2009, p. 311, grifo da autora)

Tendo isso em vista, a autora apresenta uma concepção de pesquisa baseada na perspectiva crítico-praxiológica, que se refere, basicamente, "à teoria que nasce da práxis e que retorna à práxis a fim de transformá-la” (MATEUS, 2009, p. 316).

É nesse sentido que a perspectiva crítico-praxiológica se aproxima dos paradigmas da pesquisa colaborativa, a qual, segundo Magalhães e Fidalgo (2010), permite que todas as vozes da educação sejam ouvidas e tomem parte na construção de novos significados pedagógicos. A ideia de colaboração no campo da formação docente parte da imagem dos professores como pesquisadores de suas próprias práticas (STENHOUSE, 1984), imagem esta que, por sua vez, encontra respaldo na metáfora dos professores como artistas, isto é, como profissionais que melhoram a sua arte por meio da experimentação e do exame crítico diário (STENHOUSE, 1975). Ao compreender o ensino como prática situada, Stenhouse entende que o desenvolvimento profissional docente não se realiza mediante a transmissão de teorias acadêmicas, mas, como ressalta Contreras (2002, p.118), mediante o questionamento das

[...] habilidades e recursos que refletem as capacidades pessoais com respeito à prática de ensino, ao conhecimento ministrado ou às pretensões educativas.

Na mesma linha de raciocínio, porém focalizando o contexto brasileiro, Lüdke (LÜKE, 2001; 2012; LÜKE; CRUZ, 2005) destaca a importância da pesquisa no cotidiano dos professores e, ao mesmo tempo, denuncia os obstáculos e as limitações impostas à prática da pesquisa nas escolas. Em um de seus estudos mais recentes, revela 
[...] o estado de tensão que existe entre o claro reconhecimento da exigência de integração da pesquisa na formação e no trabalho do professor e a falta de clareza sobre os caminhos para cumpri-la. (LÜDKE, 2012, p. 641-642)

Tendo como base as reflexões da autora, entendo que a pesquisa colaborativa pode ser um caminho para amenizar o referido estado de tensão. De acordo com Ibiapina (2008, p. 19), a colaboração pressupõe a participação ativa de pesquisadores e professores na reflexão acerca de problemas educacionais, levandoos a construir teorias sobre as suas práticas, a negociar crenças e valores e a interpretar "reflexiva e dialeticamente com os pares [as] suas compreensões a respeito da questão de investigação proposta”.

Essa característica possibilita a inferência de que a pesquisa colaborativa concilia duas dimensões no contexto pedagógico: a construção de saberes e a formação contínua de professores. Trata-se de uma "atividade de co-produção de conhecimento e de formação em que os pares colaboram entre si [para] resolver conjuntamente problemas que afligem a educação" (IBIAPINA, 2008, p. 25). Nas palavras de Magalhães (2002, p. 48), a pesquisa colaborativa cria um espaço em que teorias e práticas "possam ser repensadas à luz de novas compreensões e reconstruídas [...] através de negociações”.

\section{Uma breve descrição do estudo}

Este estudo se caracteriza como uma pesquisa colaborativa (IBIAPINA, 2008), tendo por objetivo refletir acerca dos aspectos e desafios da colaboração entre um pesquisador e uma professora. Configura-se, ainda, como uma pesquisa de natureza emancipatória (TELLES, 2002), abrindo espaço para a produção colaborativa de saberes no contexto investigado.

Os participantes do estudo foram um pesquisador (o autor deste artigo) da Universidade
Federal de Goiás (UFG) e uma professora da rede estadual de ensino de Goiânia (Vera). Na época da pesquisa, eu trabalhava como professor substituto na Faculdade de Letras da UFG, ministrando aulas de inglês intercultural e português intercultural no curso de licenciatura intercultural do Núcleo Takinahaky de Formação Superior Indígena. Além disso, desenvolvia minha pesquisa de mestrado em Letras e Linguística, cujo tema versava a respeito da formação crítica de professores de inglês na mesma universidade.

Já a professora Vera, formada em Letras, com habilitação em inglês, especialista em ensino de língua inglesa e participante assídua de cursos oferecidos por universidades, escolas de idiomas e secretarias de educação, estava completando 15 anos de docência na rede estadual em Goiânia. No período em que o estudo foi realizado, ela cumpria mais de 40 horas semanais: de manhã, ministrava aulas de inglês para 15 turmas; à noite, era responsável pela biblioteca da escola.

0 contexto em que foi realizada a pesquisa foi o colégio no qual a referida professora trabalhava. Apesar de lecionar em uma das escolas estaduais mais antigas e de maior prestígio da capital goiana, a professora Vera enfrentava problemas como falta de material e recursos para as aulas de inglês e falta de disciplina e interesse por parte dos alunos.

As informações foram geradas de agosto de 2010 a agosto de 2011. Nesse período, a professora Vera e eu procuramos, em colaboração: 1) refletir sobre o papel dos professores de inglês na escola; 2) identificar aspectos e desafios do ensino de inglês na rede estadual de ensino; 3) mapear a motivação dos alunos para aprender inglês; 4) elaborar estratégias humanísticas de combate à indisciplina; 5) planejar atividades que despertassem o interesse e a consciência crítica dos alunos; e 6) refletir sobre as possibilidades de transformação social a partir das aulas de inglês.

Discutimos, ainda, textos teóricos sobre ensino de inglês na educação regular pública e sobre formação de professores no Brasil. Os textos discutidos foram 0 drama do ensino de 
inglês na escola pública brasileira e 0 professor de inglês: entre a alienação e a emancipação, ambos de Maria Inês Pagliarini Cox e Ana Antônia de Assis-Peterson. Todas as sessões reflexivas foram realizadas nas dependências do colégio em que a professora trabalhava, antes ou depois das aulas ministradas por ela e por mim, já que resolvemos intercalar as práticas para que tivéssemos a oportunidade de observar e problematizar as ações de cada um em sala de aula. As sessões foram gravadas em áudio e posteriormente transcritas na forma não-verbatim, pois o objetivo era observar o conteúdo das reflexões compartilhadas e não as suas formas linguísticas.

Neste texto, utilizo informações de apenas três fontes: um questionário de pesquisa (QP), que permitiu gerar reflexões iniciais sobre o ensino de inglês na rede estadual em Goiânia; três sessões reflexivas (SR1, SR2 e SR3), que possibilitaram entrecruzar os saberes e as experiências dos participantes; e um diário de campo (DC), que permitiu registrar as minhas percepções dos encontros com a professora Vera.

A seguir, apresento e analiso as informações geradas por meio dessas três fontes de pesquisa. Tais informações apontam para dois temas de análise: no primeiro, enfatizo os aspectos iniciais da colaboração entre a professora Vera e eu; no segundo, focalizo o conteúdo das nossas sessões de reflexão colaborativa. A partir da proposta metodológica de Richardson (2000), apresento as minhas análises mesclando as linguagens de um artigo científico e de um relato de experiências.

\section{Desestabilizando hierarquias: o} início da colaboração

Um dos aspectos que mais me chamou a atenção no início da pesquisa foi a abertura da professora Vera para o diálogo. Desde o primeiro encontro, percebi que se tratava de uma profissional disposta a refletir acerca das questões educacionais e, sobretudo, interessada em melhorar sua prática. Ao corroborar as reflexões de Celani (2001) sobre o compromisso que os professores de LE devem firmar consigo mesmos, tal postura contribuiu para desestabilizar a ideia de que os professores do ensino regular não querem se desenvolver profissionalmente (ZAGURY, 2009).

No entanto, as expectativas da referida professora no que diz respeito à minha presença na escola se configuraram, em princípio, como um entrave à nossa experiência de colaboração. Durante as primeiras vezes em que nos reunimos para discutir as etapas do trabalho, ela parecia acreditar que eu estava ali simplesmente para ensiná-la, isto é, para dizer o que era bom e correto no ensino de inglês:

[...] eu cheguei com uma postura bem humilde, de quem queria aprender mesmo.

Só que essa postura acabou gerando outro entrave: eu senti que ela, a professora, está esperando muito de mim. Então, quer dizer, aconteceu exatamente o oposto [do que alguns pesquisadores relatam]: ao invés de "rejeitar" a [resistir à] "universidade", ela acha que eu estou ali [...] pra dizer o que é certo e o que é errado. (DC - pesquisador)

Acredito que as expectativas da professora Vera em relação à minha presença na escola estão, de alguma forma, relacionadas à crença de que a universidade detém as respostas e explicações para tudo o que acontece no contexto educacional. A meu ver, tal crença pode representar um forte impedimento à consolidação do trabalho colaborativo nas escolas, já que ela tende a conferir maior legitimidade ao saber acadêmico, reforçando, assim, o abismo que separa pesquisadores e professores (TELLES, 2002; MATEUS, 2009).

Inicialmente, a professora Vera parecia não acreditar em sua própria capacidade de teorizar sobre a educação, bem como na importância de suas reflexões para a formação de futuros professores de inglês, postura esta que parece decorrer de suas experiências docentes na rede estadual em Goiânia. No QP, 
ela afırma que ser professora de inglês na rede pública de ensino é "um desafio muito grande", pois se trata de uma profissão que envolve problemas como baixa remuneração salarial, despreparo profissional e desinteresse dos alunos em aprender uma língua estrangeira. São problemas como esses, também apontados por Cox e Assis-Peterson (2008), que, em meu ponto de vista, levam muitos professores, entre os quais Vera, a desacreditar sua própria capacidade de teorizar sobre a educação e de transformar a realidade na qual estão inseridos (TELLES, 2002).

Entre os problemas mencionados, o que mais parece incomodar a professora Vera é o desinteresse dos alunos em aprender inglês:

Durante muitos anos, eu venho buscando um caminho para que a maioria deles [dos alunos] aprenda um pouco que seja. Quantas e quantas vezes já saí chorando da sala de aula, frustrada com os alunos, decepcionada com o trabalho feito?! Precisamos descobrir uma forma de fazer o trabalho que nos é pedido para ser cumprido de uma maneira que vai cativar os alunos. (QP - professora Vera)

Essa fala nos permite observar não apenas o interesse, mas o comprometimento da referida professora com a formação de seus alunos (CELANI, 2001). Todavia, embora acredite que é possível ensinar e aprender inglês na escola regular pública, ela destaca a falta de colaboração entre os colegas como um dos grandes obstáculos à implementação de práticas mais efetivas em seu contexto de trabalho:

Aqui no colégio, há certos tipos de trabalho que faço sozinha, pois a religião da colega não permite, ela não se sente bem, não gosta de se envolver nesses trabalhos, e com isso os alunos dela também não participam. E isso é ruim! Precisamos nos unir para fazer um bom trabalho, de modo que o inglês possa fazer a diferença na vida dos alunos. (QP - professora Vera)

Essa visão contrasta com as minhas experiências de colaboração na universidade:

[Eu] sempre tive a oportunidade de me reunir com os colegas para discutir as minhas ações em sala de aula. Por isso, não sinto muita falta [da colaboração]. No Centro de Línguas [um projeto de ensino, pesquisa e extensão da UFG], a gente sempre costumava comentar, contar para os colegas o que a gente estava fazendo e também o que acontecia nas nossas aulas. E muitas vezes a gente também elaborava atividades em conjunto, compartilhava atividades e depois discutia sobre as aulas. (DC - pesquisador)

A necessidade do trabalho em conjunto parece ser um dos aspectos que mais contribuíram para a realização dessa experiência, já que a professora Vera alegava não ter muitas oportunidades de reflexão colaborativa na escola. E, de acordo com Magalhães e Fidalgo (2010), a colaboração é uma ferramenta essencial na formação contínua de professores, visto que abre espaço para a produção de novos significados e realidades para a educação.

Também no QP, Vera menciona um de seus maiores conflitos como professora de inglês no ensino regular público: o que fazer, como fazer e por que fazer em aulas de inglês. Todavia, em nossa primeira sessão reflexiva, ela afirma ter chegado a uma conclusão importante:

$\mathrm{Eu}$ tenho percebido, depois desses 15 anos, que não há uma receita pronta. Cada sala é diferente, é uma forma que você tem de chegar e explicar. E aí eu venho observando que a minha angústia, que o meu sofrimento de muitos anos, se esse método é melhor, outro não é... Mas, na verdade, eu estou chegando à conclusão de que a gente deve passar por um pouquinho 
de cada um deles. E, às vezes, a estratégia que você usa numa sala não dá certo na outra. (QP - professora Vera)

Nesse momento, pensei que seria interessante considerar as dificuldades em agir após a constatação de que cada sala é diferente:

[...] essa questão de analisar o contexto, Vera, eu acho muito complicado, porque, ao mesmo tempo que é uma certeza que a gente tem, que é diferente cada sala, mas... Como que a gente vai dar conta? Quantas turmas você tem? São 15?! Olha só, são 15 turmas, são 15 microculturas, você concorda? [...] [E] como que você atende a 15 microculturas diferentes? Não é fácil! (SR1 - pesquisador)

Resolvi propor essa reflexão porque, desde o início da pesquisa, notei que a professora Vera se cobrava muito, chegando, em alguns momentos, a se culpar pelas falhas de todo um sistema (tal como apontam autores como ALGEBAILE, 2009, e ZAGURY, 2009). Desse modo, pensei que, ao refletirmos a respeito das limitações de um ensino mais contextualizado, ela poderia se sentir mais aliviada, podendo agir a partir da complexidade que caracteriza a escola e a sala de aula de LE/inglês (CELANI, 2001).

Essa reflexão motivou a professora Vera a retomar o seu conflito, porém questionando a abordagem que deve ser priorizada em sala de aula:

É aquela angústia que eu te falei, que há vários anos eu venho pensando, $o$ que fazer, como fazer e por que fazer... É aquela angústia, o que é certo e o que é errado? 0 que eu devo fazer? Eu devo caminhar pra conversação, eu devo trabalhar com a leitura, com um pouco de tudo, ou vai que eu quero fazer um pouco de tudo e acabo não fazendo nada?! (SR1professora Vera)
Ao ouvir a professora, percebi que os seus questionamentos acerca do ensino de inglês dialogavam com os que eu vinha fazendo, em outro contexto:

[...] eu dou aula na Licenciatura Indígena da UFG e tem as aulas de Inglês Intercultural lá, e a gente tem muitos entraves em questão de prática, metodologia, porque a gente está descobrindo agora como fazer. Os povos indigenas representam um contexto diferente... E como que você ensina inglês, levando em consideração [essas diferenças]? Então, a gente fica: o que ensinar? É leitura? É escrita? É oralidade? Aí, eu até queria te convidar pra ir lá, um ou dois dias, nas férias, pra observar, anotar as suas dúvidas, pra ver o que você acha que é parecido, entre o que a gente faz lá e o que você faz aqui. (SR1 - pesquisador)

Acredito que a colaboração entre a professora Vera e eu se fortaleceu nesse convite, o qual partiu do reconhecimento de que, embora atuando em contextos pedagógicos distintos, compartilhávamos questionamentos bastante semelhantes em relação ao ensino de inglês. Essa postura do pesquisador abriu espaço para um intercâmbio mais efetivo de saberes, além de desestabilizar as linhas abissais que separam a universidade e a escola. 0 pesquisador e a professora estavam ali compartilhando experiências, conflitos e dúvidas, ambos aprendendo no e por meio do diálogo, atuando de forma colaborativa (TELLES, 2002; IBIAPINA, 2008; MATEUS, 2009).

\section{Entrecruzando vozes: a reflexão} colaborativa

No decorrer de nossos encontros, percebi que uma das maiores crenças da professora Vera em relação ao trabalho docente era a de que os professores não podem cometer erros e que devem saber tudo. Na SR2, por exemplo, mesmo reconhecendo que precisava mudar a sua 
prática, tentando explorar mais o conhecimento dos alunos, ela declarou:

Mas [eu] tenho aquele medo de errar, parece que eu vou puxar as coisas dos alunos e eu tenho que escrever [em inglês] no quadro o que eles pensam, o vocabulário que eles querem usar. [...] 0 conteúdo poderia fluir na sala, mas a gente fica com vergonha de errar ou de dizer que não sabe. (SR2 professora Vera)

Tendo por objetivo problematizar a declaração da professora, compartilhei com ela uma experiência pessoal:

Lembra de eu te contar da minha professora, do que eu aprendi com ela? Porque, na universidade, a gente tem a visão de que os professores sabem tudo. E não sabem! Ninguém sabe ou tem que saber tudo. E aí a gente chega lá com essa visão e ela [a referida professora], de repente, fala: "I don't know". Então, isso, pra mim, foi libertador, e eu aprendi que a gente não tem que saber tudo, se cobrar pra saber tudo, porque ninguém sabe. (SR2 - pesquisador)

Ao reconhecer que o medo de cometer erros e de não saber tudo poderia limitar a implementação de ações pedagógicas mais efetivas na escola, Vera passou a refletir a respeito de como ela poderia melhorar a sua prática:

[...] eu tenho que pensar, me organizar em casa, pensar que eu vou fazer isso com os meninos, e isso ali que surgiu e eu não souber, se tiver como a gente pesquisar na hora, a gente olha na hora e coloca o vocabulário no quadro. E, se não tivermos na hora, a gente fala que não tem a resposta nos nossos livros de apoio, mas que vamos verificar em casa, vamos consultar outros livros, consultar a internet, e dizer que eles também podem procurar e trazer a resposta na próxima aula. (SR2 - professora Vera)
Para reforçar a ideia de que os próprios alunos podem buscar respostas para suas dúvidas, resolvi compartilhar outra experiência:

Os alunos, eu lembro que eles me perguntavam assim: "Teacher, how do I say 'tal coisa' in English?", como se a gente fosse um dicionário andante. E eu falava assim: "Olha, eu não sei”. E, muitas vezes, também, eu sabia, mas eu via que o aluno estava me testando. E, quando eu percebia esse teste, eu falava: "Olha, você vai pesquisar e contar pra turma na próxima aula”. Então, assim, é bom jogar na mão deles também, porque isso ajuda a gente a lidar com essa limitação do conhecimento e promove a autonomia dos alunos. (SR2 - pesquisador)

Durante as sessões de reflexão colaborativa, pude observar que a cobrança da professora Vera em relação a si mesma, bem como a sua dificuldade em lidar com as limitações do conhecimento em sala de aula, refletiam as cobranças que são diariamente feitas aos professores do ensino regular público no Brasil. 0 sistema não lhes deixa outra saída: além de enfrentarem problemas e conflitos de toda ordem, ainda precisam realizar o seu trabalho com perfeição. Tal fato nos remete às reflexões de Zagury (2009) segundo as quais os professores estão de mãos atadas perante os alunos e a sociedade, muitas vezes impossibilitados de trabalhar pela transformação de suas próprias realidades socioeducacionais.

Toda essa discussão nos leva a considerar os entraves do ensino de inglês na escola regular pública. Ao discutir o texto de Cox e AssisPeterson (2008), a professora Vera compartilhou uma reflexão importante:

Aconteceram as mudanças, mas ainda não teve o sucesso esperado. Eu até participei da última reforma do Ensino Médio, e a gente, quando se depara com aquela situação, a gente pensa: agora, sim, o 
carro anda, vai mudar, o carro anda, vai ter sucesso agora. Só que depois, quando você vai pra prática mesmo, você vê que a esperança foi muito maior do que o resultado. (SR2 - professora Vera)

Mais adiante, ela atribuiu a culpa desse insucesso a um conjunto:

Eu acho que o erro não é só dos professores, não é só dos alunos. 0 erro é do conjunto, o erro é do sistema. Eu acho que poderia ter mais aulas de inglês, porque duas aulas é pouco; e teria também que ter interesse por parte dos alunos. Eu acho que o maior erro está aí, dos professores não terem o apoio de uma equipe pedagógica no colégio, do governo e de ter mais aulas. (SR2 - professora Vera)

Nesses excertos, a professora demonstra ter consciência das limitações impostas pelo sistema ao trabalho docente. Além disso, denuncia o abismo que separa teoria e prática, alegando que muitas vezes é essa distância que leva ao fracasso de novos projetos nas escolas. Poderíamos, então, inferir que esses projetos devem contar com a participação ativa dos professores, que terão a incumbência de colocá-los em prática. Em outras palavras, é preciso ouvir os professores em escala representativa (ZAGURY, 2009), de modo a propiciar a construção de uma narrativa polifônica no contexto educacional (COX; ASSIS-PETERSON, 2001, p. 33).

Nesse ponto, passamos a focalizar as linhas abissais (SANTOS, 2010) que separam a universidade, enquanto produtora de teoria, e a escola, enquanto lugar de prática, na produção de saberes pedagógicos. No trecho a seguir, a professora Vera destacou a importância do intercâmbio entre essas duas realidades:

[...] o que é visto na universidade não é realidade dentro das escolas. Parece que tem uma separação muito grande, está muito distante, as universidades estão muito distantes das escolas. E está precisando desse apoio [pedagógico] nas escolas mesmo. Está precisando desse apoio pra melhorar a qualidade do ensino. Essa distância precisa acabar. Eu acho que é [preciso] levar as escolas pra dentro da universidade ou trazer a universidade pra dentro das escolas. (SR2 - professora Vera)

A professora relatou, ainda, que vários professores da escola comentavam a respeito da distância que há entre o que se aprende na universidade e o que acontece nas escolas. Todavia, embora defenda que as universidades devem se inteirar melhor do que acontece nas escolas, ela não acredita que cabe àquelas ensinar tudo aos futuros professores:

Acho que a universidade não pode ensinar tudo, mas pode ensinar muita coisa, por exemplo, dizer que a gente pode se deparar com determinados tipos de aluno. Não é receita, nunca é uma receita, mas isso pode pelo menos orientar, pelo menos abrir os olhos da gente pra realidade que a gente vai enfrentar. (SR3 - professora Vera)

Na mesma linha de raciocínio, problematizei a minha experiência de formação no curso de letras, habilitação inglês, em uma universidade pública:

Eu acho que a universidade não tem que dar conta de tudo, mas eu concordo com você, que deve haver mesmo essa orientação. Nas aulas de estágio mesmo, eles aceitam a gente fazer estágio em escolas particulares, e hoje eu acho que não deveriam aceitar. Se é uma universidade pública, tem que ir pro ensino público! Eu, por exemplo, fiz o meu estágio no Centro de Linguas, porque eu dava aula lá. A minha experiência com o ensino de inglês na educação regular pública começa agora, com você. (SR3 - pesquisador) 
Além de reforçar a ideia da professora Vera, essa fala contribuiu para estabelecer um nível de colaboração ainda mais intenso entre o pesquisador e a professora. Ao afirmar que eu estava tendo a minha primeira experiência como professor-pesquisador no ensino regular público com a professora, eu disse, com outras palavras, que eu estava ali para aprender com ela, e não para ensiná-la ou para dizer o que era bom e correto no ensino de inglês, como inicialmente ela parece ter pensado. Foi essa postura que, a meu ver, possibilitou-nos desenvolver um trabalho mais colaborativo na escola e, por conseguinte, caminhar juntos na análise de problemas educacionais diversos e na implementação de possíveis mudanças (MAGALHÃES, 2002; IBIAPINA, 2008; MATEUS, 2009).

\section{Discussão e reflexões finais}

As percepções e análises apresentadas anteriormente permitem concluir que a colaboração entre a professora Vera e este pesquisador, apesar de ainda refletir certo grau de dependência do saber acadêmico para compreender e resolver problemas educacionais, foi uma experiência bastante produtiva para ambas as partes.

No primeiro tema, vimos alguns dos aspectos que marcaram o início da pesquisa, tais como a abertura da professora para o diálogo e as suas expectativas em relação à minha presença na escola. Foi muito difícil convencê-la de que os seus saberes e experiências também eram importantes para mim. Foi ainda um desafı fazê-la acreditar que eu estava ali não para dizer o que era certo ou errado, mas para compartilhar experiências e, sobretudo, para ouvi-la e aprender com ela. A desestabilização das linhas abissais que nos separam foi possível a partir das reflexões compartilhadas em nosso primeiro encontro, as quais englobaram questões como o papel dos professores de inglês na escola e as possibilidades de ensino dessa língua na rede pública. Ao refletirmos a respeito dessas questões, começamos a nos posicionar não a partir de uma hierarquia, mas de nossos respectivos saberes e experiências.

Já no segundo tema, vimos a consolidação da parceria entre a professora Vera e eu, motivada pelas reflexões compartilhadas acerca do ensino de inglês na escola e em outros contextos educacionais. Tendo em vista as cobranças que a professora fazia de si mesma, tentamos refletir, com base em nossas respectivas experiências, a respeito das limitações do conhecimento docente e das possibilidades de aprendizagem a partir dessas limitações. Nossa parceria se deu basicamente no compartilhamento de reflexões acerca de temas como as dificuldades do ensino de inglês na educação básica e o abismo que separa universidade e escola. 0 resultado foi o estabelecimento de uma aliança colaborativa, por meio do entrecruzamento de nossas vozes e reflexões acerca de questões diversas. Essas reflexões, ancoradas nos princípios dialógicos da colaboração, possibilitaram a interação e a interdependência entre os saberes, colocados em diferentes lados pelas classificações hegemônicas da ciência moderna (SANTOS, 2010).

Ambos os temas de análise mostram que a pesquisa colaborativa pode reduzir o abismo que separa pesquisadores e professores, na medida em que abre espaço para uma ecologia de saberes (SANTOS, 2010) na escola. As principais características dessa ecologia ou entrecruzamento de saberes são, a meu ver, a humildade e a confiança: a primeira refere-se à postura que os participantes, especialmente os pesquisadores, devem adotar mediante o trabalho colaborativo; a segunda refere-se ao nível de colaboração entre os participantes.

No caso deste estudo, por exemplo, o nível de colaboração chegou a tal ponto que nos sentimos à vontade para compartilhar angústias muito particulares, as quais estão intimamente relacionadas a quem somos e às nossas posturas pedagógicas. Esse nível de colaboração fez com que a professora Vera compartilhasse comigo as suas três maiores frustrações como docenteaprendiz. A primeira delas ocorreu quando uma professora de leitura e redação, após corrigir 
um texto de Vera, perguntou-lhe como havia conseguido ser aprovada no processo seletivo daquela universidade. Já a segunda aconteceu quando uma professora de estágio apontou-lhe como exemplo a não ser seguido pelos demais colegas. E, por fim, a terceira frustração ocorreu quando uma pesquisadora de pós-graduação, depois de acompanhá-la durante um semestre letivo, enviou-lhe um texto no qual evidenciava somente os aspectos negativos da escola, dos alunos e do seu trabalho. Vera confessou-me que a terceira frustração foi a que mais pesou, tanto que, após ler o texto escrito pela pesquisadora, chegou a pensar em desistir da profissão que tanto ama e da qual tanto se orgulha.

Assim sendo, cabe-nos refletir: como explicar o efeito do trabalho dessa pesquisadora na vida da professora Vera? Que papel a universidade tem cumprido na escola? Com que postura os estagiários e os pesquisadores têm se aproximado dos professores? Será que há algum tipo de colaboração ou postura colaborativa nessas pesquisas que têm sido realizadas nas escolas? Penso que devemos começar a refletir a respeito desses questionamentos o mais rápido possivel, antes que os professores comecem a desistir do seu trabalho por não se considerarem dignos e capazes de executá-lo.

Certa vez, uma professora de linguística disse mais ou menos o seguinte, remetendo-se ao papel da universidade na escola: "Eu acho que a universidade tem que dar conta de tudo!" Lembro-me que, na época, não concordei com ela, até porque não considero que a universidade tenha todo esse poder. No entanto, hoje penso que a universidade deve pelo menos tentar dar conta do máximo que ela pode ou consegue. Em outras palavras, a universidade tem voz e poder para falar e fazer. É ela que forma, todos os anos, dezenas de professores que logo irão se deparar com os problemas e as complexidades da educação regular pública. Como é possível, então, isentar-se da luta? Como é possível dizer que cada um deve cuidar do seu contexto? Não há dúvidas de que isentar-se da luta e fechar-se no seu contexto, diga-se de passagem, privilegiado, não são posturas que a universidade, como centro de formação intelectual, deve tomar em relação aos problemas da educação no Brasil. A luta é, sim, dos professores, mais do que de quaisquer outras pessoas. Mas é também dos pesquisadores, que formam professores para atuar, muitas vezes entregues à própria sorte, nessa complexa realidade.

Em relação à professora Vera, que tenta, há mais de 15 anos, driblar as limitações impostas pelo sistema (ZAGURY, 2009), não tenho dúvidas de que seus saberes e experiências são muito importantes para refletirmos sobre os desafios do ensino de inglês na educação regular pública. Atendo-nos às reflexões de Spivak (2010), que discute a impossibilidade de voz para o sujeito subalterno no centro das prioridades globais, poderíamos inferir que o grande problema é que a voz da professora, assim como todas as vozes localizadas do lado de lá da linha do pensamento abissal, não está prevista na estrutura do pensamento hegemônico ocidental.

Todavia, como já mencionado, acredito que a pesquisa colaborativa pode reduzir o abismo que separa esses dois universos, visto que possibilita uma ecologia de saberes na escola. Não se trata de uma pesquisa colaborativa na qual os pesquisadores chegam à escola, sentam-se em boas carteiras e começam a fazer as suas anotações, explorando as gafes pedagógicas dos professores e/ou as limitações estruturais da escola. Trata-se, ao contrário, de uma pesquisa colaborativa na qual pesquisadores e professores trabalham juntos, compartilhando saberes, experiências, ideias, angústias e conquistas. É uma pesquisa na qual ambos formam-se e fortalecem-se juntos, de modo a transgredir as hierarquias que os separam. Nela, as funções dos pesquisadores e professores confundem-se, desestabilizando as barreiras fronteiriças que separam os conhecimentos visíveis, acadêmicos, dos conhecimentos invisíveis, não acadêmicos.

Faz-se necessário, portanto, repensar os lugares da universidade e da escola na luta por uma educação mais digna de ser vivida. No entanto, é preciso cuidar para que não haja uma 
mera inversão de papéis, forças ou hierarquias na produção de conhecimentos pedagógicos, já que o mais interessante na proposta de colaboração é o fato de pesquisadores e professores trabalharem juntos para compreender e melhorar a educação.

Não se trata de dar voz aos professores e silenciar os pesquisadores, como tenho visto alguns colegas sugerirem. Ao fazê-lo, estamos simplesmente invertendo a matriz que tem excluído a voz dos professores da produção de conhecimentos. Além disso, como já dito, há um fato do qual não podemos escapar: universidade e escola estão intimamente relacionadas nas tessituras do sistema educacional - pois é a universidade que forma professores para atuar na complexa realidade da educação regular pública. É inútil, portanto, afırmar que os professores têm mais autoridade para falar sobre questões educacionais, deslegitimando, assim, a voz dos pesquisadores.

Aliás, penso que a palavra autoridade não tem muito a contribuir para essa discussão, visto que ela aponta diretamente para a construção e/ou reafirmação de uma hierarquia, o que, a meu ver, não deve, sob nenhuma hipótese, integrar os objetivos da pesquisa colaborativa nas escolas. Ainda que a voz dos pesquisadores e a dos professores estejam, independentemente da nossa vontade e dos nossos esforços, inscritas em diferentes matrizes de poder e saber - como pudemos observar em alguns pontos da experiência analisada neste texto. É precisamente no sentido de conversão de forças e entrecruzamento de saberes que aponto a colaboração como alternativa para desestabilizar as linhas do pensamento abissal na educação.

\section{Referências}

ALGEBAlLE, Eveline. Escola pública e pobreza no Brasil: a ampliação para menos. Rio de Janeiro: Lamparina, 2009.

CAMERON, Deborah et al. Researching language: issues of power and method. Londres: Routledge, 1992.

CELANI, Maria Antonieta Alba. Ensino de línguas estrangeiras: ocupação ou profissão. In: LEFFA, Vilson J. (Org.). 0 professor de línguas estrangeiras: construindo a profissão. Pelotas: EDUCAT, 2001. p. 23-44.

CONTRERAS, José. A autonomia de professores. São Paulo: Cortez, 2002.

COX, Maria Inês Pagliarini; ASSIS-PETERSON, Ana Antônia. 0 professor de inglês: entre a alienação e a emancipação. Linguagem \& Ensino, v. 4, n. 1, p. 11-36, 2001.

0 drama do ensino de inglês na escola pública brasileira. In: ASSIS-PETERSON, Ana Antônia (Org.). Línguas estrangeiras: para além do método. Cuiabá: EdUFMT, 2008. p. 19-54.

IBIAPINA, Ivana Maria Lopes de Melo. Pesquisa colaborativa: investigação, formação e produção de conhecimentos. Brasilia: Líber, 2008.

LEFFA, Vilson J. Aspectos políticos da formação do professor de línguas estrangeiras. In: estrangeiras: construindo a profissão. Pelotas: Educat, 2001. p. 353-376.

(Org.). 0 professor de línguas

LÜDKE, Menga. 0 professor, seu saber e sua pesquisa. Educação \& Sociedade, n. 74, p. 77-96, 2001.

CRUZ, Giseli Barreto da. Aproximando universidade e escola de educação básica pela pesquisa. Cadernos de Pesquisa, v. 35, n. 125, p. 81-109, 2005.

Desafios para a pesquisa em formação de professores. Diálogo Educacional, v. 12, n. 37, p. 629-646, 2012. 
MAGALHÃES, Maria Cecilia Camargo. 0 professor de línguas como pesquisador de sua ação: a pesquisa colaborativa. In: GIMENEZ, Telma (Org.). Trajetórias na formação de professores de línguas. Londrina: UEL, 2002. p. 39-58.

; FIDALGO, Sueli Salles. Critical collaborative research: focus on the meaning of collaboration and on mediational tools. Revista Brasileira de Linguística Aplicada, v. 10, n. 3, p. 773-797, 2010.

MATEUS, Elaine. Torres de babel e línguas de fogo: um pouco sobre pesquisa na formação de professores de inglês. Revista Brasileira de Linguística Aplicada, v. 9, n. 1, p. 307-328, 2009.

RICHARDSON, Laurel. Writing: a method of inquiry. In: DENZIN, Norman Kent; LINCOLN, Yvonna Sessions (Orgs.). Handbook of qualitative research. Thousand Oaks: Sage, 2000. p. 923-948.

SANTOS, Boaventura de Sousa. Para além do pensamento abissal: das linhas globais a uma ecologia de saberes. In:

MENESES, Maria Paula. (Org.). Epistemologias do sul. São Paulo: Cortez, 2010. p. 31-83.

SPIVAK, Gayatri Chakravorty. Pode o subalterno falar? Belo Horizonte: Editora UFMG, 2010.

STENHOUSE, Lawrence. An introduction to curriculum research and development. Londres: Heinemann, 1975. . Investigación y desarrollo del curriculum. Madri: Morata, 1984.

STETSENKO, Anna; ARIEVITCH, Igor M. Vygotskian collaborative project of social transformation: history, politics, and practice in knowledge construction. International Journal of Critical Psychology, v. 12, n. 4, p. 58-80, 2002.

TELLES, João. A. É pesquisa, é? Ah, não quero, não, bem!: sobre a pesquisa acadêmica e sua relação com a prática do professor de línguas. Linguagem \& Ensino, v. 5, n. 2, p. 91-116, 2002.

ZAGURY, Tania. 0 professor refém: para pais e educadores entenderem por que fracassa a educação no Brasil. Rio de Janeiro: Record, 2009.

Recebido em: 22.06.2012

Aprovado em: 04.02.2013

Marco Túlio de Urzêda-Freitas é mestre em Letras e Linguística pela Universidade Federal de Goiás. Atua como professor de inglês no Centro de Línguas da mesma universidade. 